\title{
Policy for the Journal of Information Technology
}

\section{Preamble}

The Association for Information Technology and its Journal was founded in 1985 by Professor Igor Alexander at Imperial College. It is appropriate to review its policy in 1989 as it relocates to the Division of Information Management at City University Business School under new editorship.

\section{Aims of the Journal}

The Journal is the mouthpiece of the Association for Information Technology and so provides an international forum for the discussion of issues that are central to the use, development and application of information and communications technology to organizations; these include public, private, small, large, national, multinational, UK based, european, and global organizations.

AIT aims to encourage the development of a body of knowledge about the use of IT in businesss organizations for the achievement of organizational goals.

The journal wishes to bridge the area between professional IT specialists, all types of users, especially managers both in general business and within IT, and academics. It looks for contributions from all these groups that are relevant to the practical issues of implementing effective IT.

\section{Representative themes}

Definition of information technology: Suitably naming and defining what 'IT' might be and indeed whether IT is a good name for the subjects under discussion.

The management of information technology: this section will cover assessment of present practice, development of improved practice, planning and implementation.

Assessment of existing IT management practice.

Evaluation of IT: methods of assessing the value of the existing and potential investment in IT to organizations; the determination of the proper IT costs; who should cost IT; who pays for IT, how are costs recovered.

Organizational change and development needed to properly exploit IT.

Corporate strategies to achieve alignment of IT and corporate business goals; the methods, tools and techniques that are used to achieve effective IT strategies.
Systems design and development methodologies and techniques.

Implementation of IT systems.

Management awareness of the potential of IT, and of competitor's investment in IT, the level of investment necessary and how to achieve this level.

Management yalue, e.g. Strassman's return on management.

The role of information, IT and systems engineering in the management of organizations

Modelling the organization to reflect the information content, the effect of information and the role of information systems. The modelling of activities and processes.

Strategy: the relationship of corporate strategies, information strategies and IT strategies.

Management support systems: their purpose, nature, effectiveness.

Co-operative work supported by computers.

Human resource aspects:

Changing cultural problems, e.g. technofear.

Employment problems: extending the pool of available employees, i.e. solutions to the demographic situation such as training women returners and ethnic minorities; telecommuting.

Management of IT staff.

Training and development and skill issues at practitioner levels.

Training and development of managers at all levels.

Training and development of users.

\section{Communications:}

Developing IT based communication systems.

Evaluation of their organizational impacts.

National policy on IT:

The role of government in the national and international context.

The funding of research, development and training. The development of policy: the contribution of professional bodies, industry bodies, trade unions and academic institutions to policy making.

\section{Technological developments}

A review of the products of IT research and development and their future impact on the use of IT.

\section{Independent standards:}

Professional standards for the development of IT professionals throughout their careers. 
Standards in IT sectors in communications, systems managements, systems development, systems implementation.

\section{Implementation of policy}

By publishing contents of a very high quality, to be achieved by a refereeing process that aims to encourage and enthuse writers while setting standards that will be visible and attractive to potential readers, and necessary for academic purposes.

The refereeing process will submit each paper intended for publication to at least two experts and an editor for detailed comment.

By building an international editorial board of experts/ specialists, from business as well as academia, in the selected fields, especially in Europe, the USA and the Far East.

By developing an editorial process that is fast as well as rigorous, that will attract practitioners, academics and consultants. Referees must be prepared to respond quickly on papers sent to them and to canvas for new contributors so that the supply of potential copy is plentiful.

\section{Contents}

These sections will be introduced as soon as possible:

Papers on current and completed research,

Proceedings of conferences,

Reports on conferences,

Reports on research programmes,

Real case studies,

Personal views,

News of relevance,

Quotes of the quarter,

Brief communications,

Letters.

Anne Leeming

Editor-in-Chief

for the Executive Committee, AIT 